\title{
Obtaining information about cancer: prevalence and preferences among Japanese adults
}

Rina Miyawaki ${ }^{1 *}$, Ai Shibata $^{2 \dagger}$, Kaori Ishii ${ }^{3+}$ and Koichiro Oka ${ }^{3+}$

\begin{abstract}
Background: Providing information about cancer prevention might increase awareness of prevention and promote preventive behaviours. A better understanding about the prevalence and preferences of obtaining information about cancer might help to identify targeted individuals and design effective strategies for promoting cancer-preventive behaviours. Thus, the present study examined the prevalence and correlates of obtaining information about cancer among Japanese adults, and described preferences including source and content.

Methods: Data were analysed for 3,058 Japanese adults (mean age $45.0 \pm 13.4$ years) who responded to an Internet-based cross-sectional survey. The data included whether information about cancer had been obtained, sources, preference for content, sociodemographic variables, health status, and cancer histories. Force-entry logistic regression analysis was used.

Results: Overall, $46.7 \%$ of respondents had obtained information about cancer. Gender, age, and education level were statistically significant correlates of doing so. Women were more likely to obtain information $(\mathrm{OR}=1.97)$ as were older age groups (40-49: $\mathrm{OR}=1.54,50-59: \mathrm{OR}=2.27,60-69: \mathrm{OR}=3.83$ ), those with higher education ( 2 years college or equivalent degree: $\mathrm{OR}=1.31$, college graduate or higher: $\mathrm{OR}=1.48$ ) and those with having cancer histories (personal: $O R=3.52$, family: $O R=1.57$, friends/co-worker: $O R=2.09$ ). The most prevalent source of information about cancer was mass media. Content of prevention is most needed among inconsistent contents with the frequently obtained contents.
\end{abstract}

Conclusions: Less than half of the respondents information about cancer. The finding suggests that better health communication strategies would be necessary to inform Japanese people about cancer. Understanding which subgroups were less likely to obtain information and preferences of information might be effective in promoting cancer prevention.

Keywords: Cancer information, Health communication, Cancer prevention, Japanese, Mass media

\section{Background}

Cancer is the leading cause of death in Japan, and over 360,000 Japanese died of it in 2011 [1]. About half of all Japanese are expected to be diagnosed with cancer during their lifetime [1], and approximately 805,000 new cancer cases were diagnosed in 2010 [2]. However, cancer mortality can be reduced through screening and early detection $[3,4]$. Thus, it is important to enhance screening in the population. Moreover, cancer incidence would be preventable through lifestyle choice and behaviour changes such as stopping smoking, reducing alcohol

\footnotetext{
* Correspondence: rina_miyawaki@akane.waseda.jp

${ }^{\dagger}$ Equal contributors

${ }^{1}$ Graduate School of Sport Sciences, Waseda University, Saitama, Japan

Full list of author information is available at the end of the article
}

consumption, eating a balanced diet, engaging in physical activity, and reducing BMI $[1,5,6]$. Indeed, the prior study estimated that $42.7 \%$ of Japanese cancer incidence and $42.6 \%$ of mortality could potentially be preventable [7]. However, general awareness of the attributable fraction of cancers being caused by major lifestyle factors was low in Japan [8].

Previous studies indicated that effective health communication could play a significant role in shaping individuals' cancer-related decisions and behaviours [9-13]. Providing information about cancer prevention such as risk factors and preventive behaviours might increase awareness of prevention and promote such behaviours.

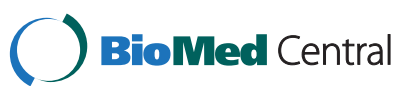

(c) 2015 Miyawaki et al.; licensee BioMed Central. This is an Open Access article distributed under the terms of the Creative Commons Attribution License (http://creativecommons.org/licenses/by/4.0), which permits unrestricted use, distribution, and reproduction in any medium, provided the original work is properly credited. The Creative Commons Public Domain Dedication waiver (http://creativecommons.org/publicdomain/zero/1.0/) applies to the data made available in this article, unless otherwise stated. 
Indeed, a number of researchers have indicated that obtaining information was positively associated with increased knowledge about cancer, and adoption of preventive and screening behaviours [14-17]. It is therefore necessary to develop effective health communication strategies that aim to inform about cancer based on solid evidence. A greater understanding about the prevalence and correlates of obtaining information about cancer might enable to identification of specific subgroup to target for interventions. Moreover, it might contribute to the design of effective strategies for promoting cancerpreventing behaviours. Several previous studies have identified that sociodemographic characteristics and cancer history were associated with cancer information seeking [9,14,18-21]. Recently, behaviours of obtaining information about cancer and the influence of obtaining cancer information on cancer preventive behaviours have been investigated by sociodemographic characteristics such as gender and race/ethnicity in the United States [10-13,22]. Nevertheless, little is known about how Japanese people obtain cancer information.

Moreover, to develop effective communication using cancer-related information, it is important to determine whether specific information sources are more effective than others and to evaluate needs for information about cancer. Hence, a number of studies about needs and sources of cancer information have been conducted with patients or their families [23]. However, few studies have assessed the preferences of the general public about sources and contents of cancer information.

Therefore, the present study examined the prevalence and demographic correlates of obtaining information about cancer among Japanese adults, and their preferences for sources and contents of cancer-related information.

\section{Methods}

\section{Study design and participants}

The current Internet-based cross-sectional study was conducted thorough a Japanese Internet research service company called MyVoice Communication, Inc. in November 2012. The company offers full-scale marketing research services, with approximately 300,000 voluntarily registered individuals, and detailed sociodemographic data for each. The sample size and parameters chosen were approximately 3,000 adult men and women aged between 20 and 69 years, with an equal number of men and women in each 10-year age bracket. Potential respondents $(n=9,767)$ were randomly and blindly selected from the registered samples and they were invited to participate in the Internet-based survey via e-mail. The number of potential respondents was determined by dividing the quota $(\mathrm{n}=300)$ and by the response rate in each stratified sample group. This rate was estimated from the results of numerous previous surveys conducted by the Internet research service company. Internet-based questionnaires were placed in a protected area of a web site and potential respondents received a URL in an invitation e-mail. After more than 300 participants in each group had responded to the survey, acceptance of further participants was stopped in each group. A total of 3,292 respondents (response rate: $33.7 \%$ ) voluntarily clicked on the "agree" button at the end of an online informed consent form and completed the questionnaire. Reward points valued at 70 yen were provided as incentives for participation (1 US dollar was equivalent to approximately 82 yen in 2012). The study was approved by the Ethics Committee of Waseda University, Japan.

\section{Measurements \\ Prevalence and demographic correlates of obtaining information about cancer}

Participants were asked if they had obtained information about cancer from any source (had obtained/ had not obtained, yet). Possible sociodemographic correlates of obtaining information about cancer included gender, age (classified in years as 20-29, 30-39, 40-49, 50-59 and 60-69 years), marital status (currently married or not), education level (less than high school graduate, 2 years college or equivalent or college graduate), employment status (employed or not) and household income level (less than 5,000,000 yen, 5,000,000-10,000,000 yen and $10,000,000$ yen or more). Health status was classified as good (very good and good) or poor (not good, poor, or don't know). Personal, family and friend/co-worker cancer histories were categorized as having a history of cancer or not.

\section{Preferences for sources and contents of cancer-related information}

Participants were asked about the contents of cancer-related information both obtained and needed. The content options of cancer-related information were prevention, symptoms, screening/testing/early detection, diagnosis, treatment, prognosis or recovery, coping, medicine, medical expenses, cancer organization, alternative treatment, other and nothing. Respondents who only indicated that they had obtained information about cancer were asked about their information sources with multiple responses available (healthcare provider, family or friend, television or radio, Internet, newspaper, magazine, brochure or pamphlet, book, government health agency, other).

\section{Statistical analysis}

For the analysis, respondents with incomplete information were excluded $(n=234)$. Data were analysed for 3,058 people who provided complete information for the study variables. Chi-square tests were used to 
determine proportional differences between sociodemographic characteristics and whether or not the respondent had obtained information about cancer. A forced-entry logistic regression analysis was conducted to examine whether sociodemographic variables, perception of own health status and cancer history were related to obtaining information about cancer. Odds rations (ORs) and their 95\% confidence intervals (CIs) were calculated. Statistical analyses were performed using SPSS for Windows version 22.0 J (Statistical Package for the Social Sciences; SPSS Inc., Chicago, IL, USA).

\section{Results}

\section{Basic respondent characteristics}

The respondent characteristics are summarized in Table 1. For the total sample, the mean age was $45.0 \pm$ 13.4 years. Overall, $49.5 \%$ of samples were men, $64.4 \%$ were married, and $52.6 \%$ were employed. Of the respondents, $48.6 \%$ had graduated from college or graduate school, whereas $26.6 \%$ had less than a high school diploma. Twelve percent of the sample had a household income of more than $10,000,000$ yen $(10,000,000$ yen was equivalent to approximately 122,000 US dollars) per year, whereas $46.2 \%$ earned less than $5,000,000$ yen $(5,000,000$ yen was equivalent to approximately 61,000 US dollars) per year. Moreover, $4.1 \%$ had a personal history of cancer, $41.9 \%$ reported family history, and $45.2 \%$ reported a friend/co-worker history. More than three quarters, $76.1 \%$, reported good health.

\section{Prevalence and correlates of obtaining information about cancer}

Overall, 46.7\% ( $\mathrm{n}=1,458)$ of respondents had obtained information about cancer. Table 2 presents the results of the forced-entry regression analysis. Gender, age, and education level were the demographic factors with a statistically significant correlation to obtaining information about cancer. Women were more likely to obtain information about cancer than men $(\mathrm{OR}=1.97,95 \% \mathrm{CI}=$ 1.64-2.39). Respondents aged $40-49$ years $(\mathrm{OR}=1.54$, $95 \% \mathrm{CI}=1.17-2.03)$ or older (age $50-59$ years: $\mathrm{OR}=$ 2.27, $95 \% \mathrm{CI}=1.71-3.02$; age $60-69$ years: $\mathrm{OR}=3.83$, $95 \% \mathrm{CI}=2.84-5.16)$ were positively associated with obtaining information about cancer. Those with 2 years college or equivalent degree $(\mathrm{OR}=1.31,95 \% \mathrm{CI}=1.05-$ 1.64) and college graduates or higher ( $\mathrm{OR}=1.48,95 \%$ $\mathrm{CI}=1.21-1.81)$ were more likely to report obtaining information about cancer than the reference. In addition, respondents who perceived their health to be good $(\mathrm{OR}=1.23,95 \% \mathrm{CI}=1.02-1.48)$ were also more likely to obtain information about cancer than those who perceived their health to be poor. Previous experience of cancer in self, family or friend was positively associated with obtaining information about cancer (respondents with cancer diagnosis: $\mathrm{OR}=3.52,95 \% \mathrm{CI}=2.12-5.85$; having family cancer history: $\mathrm{OR}=1.57,95 \% \mathrm{CI}=$ 1.34-1.85; having friends/co-worker with cancer history: $\mathrm{OR}=2.09,95 \% \mathrm{CI}=1.77-2.47$ ).

\section{Cancer information preferences}

Table 3 shows preferred sources of information about cancer. The most prevalent cancer information sources among Japanese people were mass media. The most reported source was television/radio (68.4\%) followed by the Internet (63.7\%), and newspaper (43.3\%). Approximately $40 \%$ of respondents obtained information from either family or friend $(41.0 \%)$ or health care provider (38.5\%).

Table 4 shows the content of the cancer-related information that participants obtained and expected to obtain. Of the total, $16.9 \%$ of respondents obtained information about screening or testing, $13.5 \%$ about symptoms, and $12.8 \%$ about treatment. The other side, the most frequently wanted content of the cancer-related information was screening or testing (43.7\%) followed by symptoms $(34.5 \%)$ as well as obtained content. Around one third, $34 \%$ of respondents needed the information about prevention. The percentage of respondents who expected to obtain information about prevention was higher than the percentage that actually obtained it.

\section{Discussion}

This is the first study assessing behaviours and preferences around obtaining information about cancer in Japan. Information about cancer had been obtained by less than half of those responding, which was similar to levels seen in previous studies [18,20,21,24]. However, this level may not be sufficient. This result implies that efforts to inform people about cancer might be not enough to reach a large proportion of the population. Effective health communication strategies about cancer are therefore required to promote cancer preventing lifestyle changes, including attending cancer screening.

The current study found that some sociodemographic characteristics are significantly correlated with obtaining information about cancer. Women were more likely to obtain information about cancer, which is consistent with previous studies $[6,18,21]$. In contrast, the number of deaths from and incidence of cancer was larger in men. The results suggest that a communication strategy focused on men is particularly important. Older age groups were found to be more likely to obtain information about cancer among Japanese adults. This result is inconsistent with prior studies that indicated older respondents were less likely to seek information about cancer $[18,20,21,25]$. People often tend to seek and receive cancer information from mass media including television and print media [26]. In Japan, older people 
Table 1 Sociodemographic characteristics, health status, cancer history of study participants $(n=3,058)$

\begin{tabular}{|c|c|c|c|c|c|c|c|}
\hline & \multirow{2}{*}{\multicolumn{2}{|c|}{ Total }} & \multicolumn{4}{|c|}{ Obtained information about cancer } & \multirow{3}{*}{$x^{2} p$ value } \\
\hline & & & \multicolumn{2}{|c|}{ Yes $(n=1,458)$} & \multicolumn{2}{|c|}{ No $(n=1,600)$} & \\
\hline & $\mathrm{n}$ & $\%$ & $\mathrm{n}$ & $\%$ & $\mathrm{n}$ & $\%$ & \\
\hline \multicolumn{8}{|l|}{ Gender } \\
\hline Men & 1,513 & 49.5 & 590 & 40.5 & 923 & 57.7 & $* * *$ \\
\hline Women & 1,545 & 50.5 & 868 & 59.5 & 677 & 42.3 & \\
\hline \multicolumn{8}{|l|}{ Age } \\
\hline $20-29$ & 544 & 17.8 & 158 & 10.8 & 386 & 24.1 & $* * *$ \\
\hline 30-39 & 632 & 20.7 & 224 & 15.4 & 408 & 25.5 & \\
\hline $40-49$ & 622 & 20.3 & 272 & 18.7 & 350 & 21.9 & \\
\hline $50-59$ & 629 & 20.6 & 363 & 24.9 & 266 & 16.6 & \\
\hline $60-69$ & 631 & 20.6 & 441 & 30.2 & 190 & 11.9 & \\
\hline \multicolumn{8}{|l|}{ Marital status } \\
\hline Unmarried & 1,090 & 35.6 & 411 & 28.2 & 679 & 42.4 & $* * *$ \\
\hline Married & 1,968 & 64.4 & 1,047 & 71.8 & 921 & 57.6 & \\
\hline \multicolumn{8}{|l|}{ Education } \\
\hline Less than high school graduate & 814 & 26.6 & 368 & 25.2 & 446 & 27.9 & * \\
\hline 2 years college or equivalent & 758 & 24.8 & 391 & 26.8 & 367 & 22.9 & \\
\hline College graduate & 1,486 & 49.5 & 699 & 47.9 & 787 & 49.2 & \\
\hline \multicolumn{8}{|l|}{ Employment status } \\
\hline Not employed & 1,451 & 47.4 & 793 & 54.4 & 658 & 41.1 & $* * *$ \\
\hline Employed & 1,607 & 52.6 & 665 & 45.6 & 942 & 58.9 & \\
\hline \multicolumn{8}{|l|}{ Household income } \\
\hline$<5,000,000$ yen & 1,412 & 46.2 & 647 & 44.4 & 765 & 47.8 & $* *$ \\
\hline$<10,000,00$ yen & 1,278 & 41.8 & 609 & 41.8 & 669 & 41.8 & \\
\hline$\geq 10,000,000$ yen & 368 & 12.0 & 202 & 13.9 & 166 & 10.4 & \\
\hline \multicolumn{8}{|l|}{ Health status } \\
\hline Poor & 731 & 23.9 & 319 & 21.9 & 412 & 25.8 & * \\
\hline Good & 2,327 & 76.1 & 1,139 & 78.1 & 1,188 & 74.3 & \\
\hline \multicolumn{8}{|l|}{ Cancer history (Self) } \\
\hline No & 2,934 & 95.9 & 1,354 & 92.9 & 1,580 & 98.8 & $* * *$ \\
\hline Yes & 124 & 4.1 & 104 & 7.1 & 20 & 1.3 & \\
\hline \multicolumn{8}{|l|}{ Cancer history (Family) } \\
\hline No & 1,776 & 58.1 & 699 & 47.9 & 1,077 & 67.3 & $* * *$ \\
\hline Yes & 1,282 & 41.9 & 759 & 52.1 & 523 & 32.7 & \\
\hline \multicolumn{8}{|l|}{ Cancer history (Friend/co-worker) } \\
\hline No & 1,682 & 55.0 & 587 & 40.3 & 1,095 & 68.4 & $* * *$ \\
\hline Yes & 1,383 & 45.2 & 878 & 60.2 & 505 & 31.6 & \\
\hline
\end{tabular}

Abbreviations. ${ }^{*} \mathrm{p}<0.05,{ }^{* *} \mathrm{p}<0.01,{ }^{* * *} \mathrm{p}<0.001$.

tend to watch more television [27] and have a higher rate of newspaper subscriptions [28] than other age groups. Thus, older age groups may also have more opportunity to obtain information about cancer. The finding suggests that the information about cancer is not reaching younger people compared to older people. It is important for a young age to adopt preventive behaviours before getting cancer. Furthermore, cancer has been increasing across all age groups, including younger people recently [1]. Thus, greater effort to inform younger people is needed. Respondents with a previous history of cancer or those with family, friends, or co-workers having a history of cancer were more likely to obtain information about cancer. Experience of 
Table 2 Multivariate logistic models for obtaining information about cancer

\begin{tabular}{|c|c|c|c|c|c|c|}
\hline & OR & $(95 \% \mathrm{Cl})$ & $p$ value & AOR & $(95 \% \mathrm{Cl})$ & $p$ value \\
\hline \multicolumn{7}{|l|}{ Gender } \\
\hline Women & 2.01 & $(1.72 .32)$ & $* * *$ & 1.97 & $(1.64-2.39)$ & $* * *$ \\
\hline \multicolumn{7}{|l|}{ Age } \\
\hline $20-29$ & 1 & (ref) & & 1 & (ref) & \\
\hline $30-39$ & 1.34 & $(1.05-1.72)$ & * & 1.24 & $(0.95-1.63)$ & \\
\hline $40-49$ & 1.90 & $(1.49-2.42)$ & $* * *$ & 1.54 & $(1.17-2.03)$ & $* *$ \\
\hline $50-59$ & 3.33 & $(2.61-4.25)$ & $* * *$ & 2.27 & $(1.71-3.02)$ & $* * *$ \\
\hline $60-69$ & 5.67 & $(4.41-7.29)$ & $* * *$ & 3.83 & $(2.84-5.16)$ & $* * *$ \\
\hline \multicolumn{7}{|l|}{ Marital status } \\
\hline Married & 1.88 & $(1.62-2.19)$ & $* * *$ & 1.04 & $(0.86-1.25)$ & \\
\hline \multicolumn{7}{|l|}{ Education } \\
\hline Less than high school graduate & 1 & (ref) & & 1 & (ref) & \\
\hline 2 years college or equivalent & 1.29 & $(1.06-1.57)$ & & 1.31 & $(1.05-1.64)$ & * \\
\hline College graduate & 1.08 & $(0.91-1.28)$ & * & 1.48 & $(1.21-1.81)$ & $* * *$ \\
\hline \multicolumn{7}{|l|}{ Employment status } \\
\hline Employed & 0.59 & $(0.51-0.68)$ & $* * *$ & 0.88 & $(0.73-1.07)$ & \\
\hline \multicolumn{7}{|l|}{ Household income } \\
\hline$<5,000,000$ yen & 1 & (ref) & & 1 & (ref) & \\
\hline$<10,000,00$ yen & 1.08 & $(0.93-1.25)$ & $* *$ & 0.99 & $(0.84-1.19)$ & \\
\hline$\geq 10,000,000$ yen & 1.44 & $(1.14-1.81)$ & & 1.24 & $(0.95-1.61)$ & \\
\hline \multicolumn{7}{|l|}{ Health status } \\
\hline Good & 1.24 & $(1.05-1.46)$ & * & 1.23 & $(1.02-1.48)$ & $*$ \\
\hline \multicolumn{7}{|l|}{ Cancer History (Self) } \\
\hline Yes & 6.07 & $(3.74-9.85)$ & $* * *$ & 3.52 & $(2.12-5.85)$ & $* * *$ \\
\hline \multicolumn{7}{|l|}{ Cancer History (Family) } \\
\hline Yes & 2.24 & $(1.93-2.59)$ & $* * *$ & 1.57 & $(1.34-1.85)$ & $* * *$ \\
\hline \multicolumn{7}{|l|}{ Cancer History (Friend/co-worker) } \\
\hline Yes & 3.28 & $(2.83-3.81)$ & $* * *$ & 2.09 & $(1.77-2.47)$ & $* * *$ \\
\hline
\end{tabular}

Abbreviations. OR odds ratio, $\mathrm{Cl}$ confidence interval, ref referent group. ${ }^{*} \mathrm{p}<0.05,{ }^{* *} \mathrm{p}<0.01,{ }^{* * *} \mathrm{p}<0.001$.

feeling closer to cancer might enhance their interest in cancer compared with those not having cancer history.

This study also examined the preferred sources of information about cancer. Mass media such as television/radio, Internet, and newspaper were the most common source of information about cancer among Japanese adults. These findings were consistent with those of other studies $[12,18,21]$. Previous study indicated that mass media had a considerable influence on cancer communications, because it could attract and hold the attention of those at cancer risk [29]. Moreover, attracting and holding public attention through mass media could help motivate individual behavioural change [26]. The effective use of mass media could contribute to delivering cancer information to Japanese adults. Therefore, future research should explore specific and effective ways to using mass media.
Table 3 Source of information for participants who had obtained information about cancer $(n=1,458)$

\begin{tabular}{lll}
\hline & \multicolumn{2}{l}{ Source of cancer information } \\
\cline { 2 - 3 } Information source & $\mathbf{n}$ & \% \\
\hline Health care provider & 561 & 38.5 \\
Family, Friend & 598 & 41.0 \\
Television, Radio & 997 & 68.4 \\
Internet & 929 & 63.7 \\
Newspaper & 631 & 43.3 \\
Magazine & 311 & 21.3 \\
Broshure, Pamphlet & 225 & 15.4 \\
Book & 227 & 15.6 \\
Government health agency & 243 & 16.7 \\
Other & 18 & 1.2 \\
\hline
\end{tabular}

Respondents are not mutually exclusive. 
Table 4 Content of cancer-related information that participants obtained and needed $(n=3,058)$

\begin{tabular}{llllll}
\hline & \multicolumn{2}{l}{$\begin{array}{l}\text { Obtained } \\
\text { information }\end{array}$} & & \multicolumn{2}{l}{$\begin{array}{l}\text { Needed } \\
\text { information }\end{array}$} \\
\cline { 2 - 3 } \cline { 6 - 7 } Contents of information & $\mathbf{n}$ & $\%$ & & $\mathbf{n}$ & $\%$ \\
\cline { 1 - 2 } Screening/Testing/Early detection & 516 & 16.9 & & 1,336 & 43.7 \\
Symptoms & 414 & 13.5 & & 1,056 & 34.5 \\
Treatment cure & 391 & 12.8 & & 1,019 & 33.3 \\
Prevention & 299 & 9.8 & & 1,041 & 34.0 \\
Diagnosis & 272 & 8.9 & & 766 & 25.0 \\
Medical expenses & 206 & 6.7 & & 630 & 20.6 \\
Medicine & 193 & 6.3 & & 630 & 20.6 \\
Cancer organization & 130 & 4.3 & & 517 & 16.9 \\
Prognosis/recovery & 104 & 3.4 & & 479 & 15.7 \\
Coping & 84 & 2.7 & & 546 & 17.9 \\
Alternative treatment & 69 & 2.3 & & 328 & 10.7 \\
Other & 2 & 0.1 & & 10 & 0.3 \\
\hline
\end{tabular}

Respondents are not mutually exclusive.

Additionally, the present study revealed the contents of cancer information both obtained and needed. The most frequently obtained content was about screening, symptoms, and treatment, which is consist with a previous survey $[18,30]$. In the present study, contents of cancer information which respondents needed were similar to contents which respondents obtained. However, some needed contents of cancer information were inconsistent with the frequently obtained content such as prevention, medical expenses, and coping. The finding suggests that it is necessary to provide additional information to satisfy expectations. In particular, contents of prevention are needed to inform because it was the most needed information among inconsistent contents of information. This might also increase awareness and promote behavioural change to support cancer prevention. Mass media, which was the main cancer information source, might be able to provide information about cancer prevention effectively. However, previous studies indicated that mass media tend to focus on cancer treatment and patients rather than on prevention [31-33]. Furthermore, the distinctive characteristics of Japanese mass media coverage are not well understood. Thus, additional research on how cancer information is presented by Japanese mass media is needed.

The current study had some limitations. First, this study was conducted in an Internet setting. Selection bias is a major factor known to limit the generalizability of results in the Internet survey. It occurs because of the non-representative nature of the Internet population and the self-selection of participants [34,35]. However, this study has random selection of participants, an equally distributed gender (men or women) and age group
(20-69 years) from a pool of 300,000 people. These may have helped to mitigate bias and ensure greater representativeness in the survey. Second, data are susceptible to responder bias because of self-reported data. Third, the present study used a self-administered questionnaire to examine obtaining information about cancer. Although the questionnaire was adopted from the previous survey, psychometric properties of scales had not evaluated. Therefore, the reliability and validity of the scales were insufficient. Finally, present study was the lack of clarity between active and passive information obtaining behaviours. Furthermore, lack of differentiating between obtaining information for one-self and obtaining information for others was another limitation.

\section{Conclusions}

The prevalence of individuals obtaining information about cancer among Japanese adults through internetbased study was not sufficient. The result highlights a need for effective health communication strategies to inform people about cancer. In particular, communication efforts should be targeted towards men and younger people. Additionally, mass media was the most common source of information about cancer, and information was required about prevention as well as screening, symptoms and treatment. The present study would contribute to the development of health communication strategies to providing Japanese people with information about cancer by understanding subgroup with low obtaining information and preferences including information source and content.

\section{Competing interests}

The authors declare that they have no competing interests.

\section{Authors' contributions}

RM was involved in the design of the study, analysis and interpretation of the data, and drafting of the manuscript. AS, Kl, and $\mathrm{KO}$ were involved in the design and coordination of the study and helped to draft the manuscript. All authors read and approved the final manuscript.

\section{Acknowledgments}

This work was supported in part by the National Cancer Center Research and Development Fund (26-A-31) from the Japanese Ministry of Health, Labour and Welfare and the Grants-in-Aid for Scientific Research (No. 22700681) from the Japan Society for the Promotion of Science.

\section{Author details}

'Graduate School of Sport Sciences, Waseda University, Saitama, Japan.

${ }^{2}$ Faculty of Health and Sport Sciences, University of Tsukuba, Ibaraki, Japan.

${ }^{3}$ Faculty of Sport Sciences, Waseda University, Saitama, Japan.

Received: 31 October 2014 Accepted: 5 February 2015

Published online: 14 February 2015

\section{References}

1. Foundation for Promotion of Cancer Research. Cancer statistics in Japan2013. Tokyo: Foundation for Promotion of Cancer Research; 2013.

2. National cancer center, Center for cancer control and information services. Monitoring of Cancer Incidence in Japan, MCIJ2010. 2014. 
[http://ganjoho.jp/data/professional/statistics/odjrh3000000hwsa-att/ mcij2010_report.pdf] (in Japanese). [Accessed 31 October 2014].

3. American Cancer Society. Cancer Prevention \& Early Detection Facts and Figures 2013. Atlanta: American Cancer Society; 2013.

4. World Health Organization. Cancer; Screening for various cancers. [http:// www.who.int/cancer/detection/variouscancer/en/] [Accessed 31 October 2014].

5. World Cancer Research Fund/American Institute for cancer research. Food, nutrition, physical activity, and the prevention of cancer: a global perspective. Washington, DC: American Institute for cancer research; 2007.

6. World Health Organization. Diet, nutrition and the prevention of chronic diseases Report of the joint WHO/FAO expert consultation. 916th ed. Geneva: WHO technical report series; 2013. p. 95-104.

7. Inoue M, Sawada N, Matsuda T, Iwasaki M, Sasazuki S, Shimazu T, et al. Attributable causes of cancer in Japan in 2005-systematic assessment to estimate current burden of cancer attributable to known preventable risk factors in Japan. Ann Oncol. 2012;23(5):1362-9.

8. Inoue M, Iwasaki M, Otani T, Sasazuki S, Tsugane S. Public awareness of risk factors for cancer among the Japanese general population: A populationbased survey. BMC Public Health. 2006;6:2.

9. Arora NK, Hesse BW, Rimer BK, Viswanath K, Clayman ML, Croyle RT. Frustrated and confused: the American public rates its cancer-related information-seeking experiences. J Gen Intern Med. 2008;23(3):223-8.

10. Vanderpool RC, Kornfeld J, Rutten LF, Squiers L. Cancer information-seeking experiences: the implications of Hispanic ethnicity and Spanish language. J Cancer Educ. 2009;24(2):141-7.

11. Beaudoin CE, Fernandez C, Wall JL, Farley TA. Promoting health eating and physical activity short term effect of a mass media campaign. Am J Prev Med. 2007;32(3):217-23.

12. Oh KM, Kreps GL, Jun J, Chong E, Ramsey L. Examining the health information-seeking behaviors of Korean Americans. J Health Commun. 2012;17:779-801.

13. Griffith DM, Ellis KR, Allen JO. How does health information influence African American men's health behavror? Am J Mens Health. 2012;6(2):156-63.

14. Shim M, Kelly B, Hornik R. Cancer information scanning and seeking behavior is associated with knowledge, lifestyle choices, and screening. J Health Commun. 2006:11(S1):157-72.

15. Beaudoin CE, Hong T. Health information seeking, diet and physical activity: an empirical assessment by medium and critical demographics. Int J Med Inform. 2011;80(8):586-95.

16. Rutten LJ, Augustson EM, Doran KA, Moser RP, Hesse BW. Health information seeking and media exposure among smokers: a comparison of light and intermittent tobacco users with heavy users. Nicotine Tob Res. 2009;11(2):190-6.

17. Hay J, Coups EJ, Ford J, DiBonaventura M. Exposure to mass media health information, skin cancer beliefs, and sun protection behaviors in a United States probability sample. J Am Acad Dermatol. 2009;61(5):783-92.

18. Rutten $L$, Squiers L, Hesse B. Cancer-related information seeking: Hints from the 2003 Health Information National Trends Survey (HINTS). J Health Commun. 2006;11(S1):147-56

19. Niederdeppe J, Frosch DL, Hornik RC. Cancer news coverage and information seeking. J Health Commun. 2008;13(2):181-99.

20. Kelly B, Hornik R, Romantan A, Schwartz JS, Armstrong K, DeMichele A, et al. Cancer information scanning and seeking in the general population J Health Commun. 2010;15(7):734-53.

21. Tortolero-Luna G, Finney Rutten LJ, Hesse BW, Davis T, Kornfeld J, Sanchez $M$, et al. Health and cancer information seeking practices and preferences in Puerto Rico: creating an evidence base for cancer communication efforts. J Health Commun. 2010;15(3):30-45.

22. Nguyen GT, Bellamy SL. Cancer information seeking preferences and experiences: disparities between Asian Americans and Whites in the Health Information National Trends Survey (HINTS). J Health Commun. 2006;11 (S1):173-80.

23. Rutten LF, Arora NK, Bakos AD, Aziz N, Rowland J. Information needs and sources of information among cancer patients: a systematic review of research (1980-2003). Patient Educ Couns. 2005;57:250-61.

24. National Cancer Institute. Health Information National Trends Survey. 2014 [http://hints.cancer.gov/question-details.aspx?dataset=43\&method=mail\&qid=401] [Accessed 31 October 2014].

25. Ramanadhan S, Viswanath K. Health and the information nonseeker: a profile. Health Commun. 2006;20(2):131-9.
26. Hannon $P$, Lloyd GP, Viswanath $K$, Smith T, Basen-Engquist $K$, Vernon SW, et al. Mass media and marketing communication promoting primary and secondary cancer prevention. J Health Commun. 2009;14(S1):30-7.

27. Institute for Information and Communications Policy: National survey on usage time and status of telecommunication media. 2013, [http://www.soumu.go.jp/ iicp/chousakenkyu/data/research/survey/telecom/2013/01_h24mediarmedi_ houkokusho.pdf] (in Japanese). [Accessed 31 October 2014].

28. The Japan Newspaper Publishers \& Editors Association. 2013 National Survey about Media Contact and Evaluation. 2014. [http://www.pressnet.or. jp/adarc/data/research/pdf/2013media/report_web_2013.pdf] (in Japanese). [Accessed 31 October 2014].

29. Stephenson MT, Southwell BG. Sensation seeking, the activation model, and mass media health campaigns: Current findings and future directions for cancer communication. J Commun. 2006;56:S38-56.

30. Cho J, Noh HI, Ha MH, Kang SN, Choi JY, Chang YJ. What kind of cancer information do Internet users need? Support Care Cancer. 2011;19(9):1465-9.

31. Slater MD, Long M, Bettinghaus EP, Reineke JB. News coverage of cancer in the United States: a national sample of newspapers, television, and magazines. J Health Commun. 2008;13(6):523-37.

32. Jensen JD, Moriarty CM, Hurley RJ, Stryker JE. Making sense of cancer news coverage trends: a comparison of three comprehensive content analyses. J Health Commun. 2010;15(2):136-51.

33. Stryker JE, Emmons KM, Viswanath K. Uncovering differences across the cancer control continuum: a comparison of ethnic and mainstream cancer newspaper stories. Prev Med. 2007;44(1):20-5.

34. Eysenbach $G$, Wyatt J. Using the Internet for surveys and health research. J Med Internet Res. 2002;4(2):E13.

35. Rhodes SD, Bowie DA, Hergenrather KC. Collecting behavioural data using the world wide web: considerations for researchers. J Epidemiol Community Health. 2003;57(1):68-73.

\section{Submit your next manuscript to BioMed Central and take full advantage of:}

- Convenient online submission

- Thorough peer review

- No space constraints or color figure charges

- Immediate publication on acceptance

- Inclusion in PubMed, CAS, Scopus and Google Scholar

- Research which is freely available for redistribution

Submit your manuscript at www.biomedcentral.com/submit
C BioMed Central 